\title{
CELEBRACIONES TERESIANAS EN EL SIGLO DE ORO
}

\author{
POR \\ IGNACIO ARELLANO ${ }^{1}$ \\ GRISO. Universidad de Navarra
}

\section{RESUMEN}

El artículo estudia, a partir de las relaciones de fiestas y otra documentación, las celebraciones por la beatificación y canonización de Santa Teresa, examinando la estructura de la fiesta y sus elementos: procesiones, función de las alegorías, técnicas emblemáticas, certámenes poéticos, escenografía y representaciones teatrales... para mostrar el doble objetivo de exaltación hagiográfica doctrinal y diversión popular de estos eventos festivos.

PALABRAS CLAVE: Santa Teresa; fiesta hagiográfica; relaciones de sucesos; Siglo de Oro.

\section{TERESIAN CELEBRATIONS IN THE GOLDEN AGE}

\section{ABSTRACT}

This article studies - on the basis of informations provided by the literary genre of the relaciones de sucesos, relations of events-, the celebrations for the beatification and canonization of Santa Teresa, examining the structure of the hagiographic feast and its elements: processions, allegories, emblematic techniques, poetic certámenes, religious ceremonies, staging and theatrical performances... to show the dual objective of doctrinal hagiographic exaltation and popular recreation of these events.

KEY WORDS: Santa Teresa; Hagiographic feast; Relations of events; Golden Age.

Cómo CITAR ESTE ARTículo / CITATION: Arellano, I. 2018. «Celebraciones teresianas en el Siglo de Oro». Hispania Sacra 70, 141: 283-293. https://doi.org/10.3989/hs.2018.021

\author{
Recibido/Received 14-05-2016 \\ Aceptado/Accepted 21-06-2016
}

\section{LAS FIESTAS HAGIOGRÁFICAS, SÍNTESIS DE MÚLTIPLES VERTIENTES}

Bien conocido es el desarrollo de los fastos públicos en el Barroco. García Bernal (2006) ha dedicado no hace mucho un extenso volumen sobre el fasto público en la España de los Austrias, con notables análisis sobre las funciones comunicativas, dispositivos ceremoniales, dimensiones espectaculares, etc., en donde no falta un capítulo centrado en los "triunfos sagrados", que inserta en el marco general de los fastos, con sus propias especificidades:

Los espectáculos religiosos responden a la propia necesidad de autoexaltación de las poderosas fundaciones religiosas que los patrocinan. Estas tratan de asegurar una cadena de adhesiones que incorpora el poder civil y contribuye a engrandecer el prestigio de la

1 iarellano@unav.es / ORCID iD: http://orcid.org/0000-00023386-3668

2 Tomo algunas líneas de la introducción a Arellano 2009b. orden. Conforme avanza el siglo del Barroco la maquinaria del espectáculo sagrado estará tan arraigada en el gusto popular que su lenguaje y sus prácticas celebrativas resultan imprescindibles para solemnizar cualquier acto social. ${ }^{3}$

Habría que matizar algo esta afirmación, pues en España al menos las celebraciones hagiográficas (en general los fastos religiosos) no son únicamente propiciados por las órdenes o instituciones religiosas, sino que se impulsan desde numerosas iniciativas (desde caballeros particulares a las cofradías populares) más allá de las instancias que se pueden denominar "del poder» que son sin duda las principales dirigentes. ${ }^{4}$ Esto no significa que las iniciativas más popula-

3 García Bernal 2006: 263.

4 Es significativa la comparación de las fiestas jesuíticas por beatificaciones y canonizaciones de San Ignacio y San Francisco Javier celebradas en España y en Francia: en Francia todas las relaciones ponderan sistemáticamente la responsabilidad del rey en las celebraciones, que 
res se sitúen enfrente de las nacidas en más altos niveles de la jerarquía aristocrática, sino que se produce una unidad de sentido, en la cual la fiesta (la religiosa especialmente) ${ }^{5}$ funciona desde este punto de vista como un mecanismo de "transferencia de modelos del mundo desde sus detentadores dirigentes hacia la clientela masiva ${ }^{6}$, clientela que admite y multiplica en sus propias iniciativas toda la «máquina» celebrativa.

La fiesta hagiográfica manifiesta además, de modo privilegiado, la presencia de los santos en la sociedad de la época y su función ejemplar, en el marco de la "gran eclosión del culto de dulía con que la liturgia católica venerará a los santos a partir del Concilio de Trento". ${ }^{7}$ Esta ejemplaridad la apunta Lope de Vega en su relación de las fiestas de San Isidro, donde evoca a los otros canonizados en la misma ocasión, Santa Teresa entre ellos ${ }^{8}$ :

En este tiempo finalmente llegaron las nuevas a la patria común de todos, con no menos alegría que por Isidro por los demás santos, viendo que en tiempo de tantos heresiarcas y seudoprofetas nuestro beatísimo padre ilustraba la Iglesia de España, como en premio de su lealtad, de cuatro tan heroicos santos para todos géneros de estados: un labrador para humildes, un humilde para sabios, un sabio para gentiles y una mujer fuerte $^{9}$ para la flaqueza de las que en tantas provincias aflige el miedo (prólogo, sin paginación).

La fiesta hagiográfica invade todos los escenarios, sacros y profanos, y se desarrolla en el interior de las iglesias y en los espacios exteriores de la ciudad, involucrando a todas las categorías sociales - cada una en su pape ${ }^{10}-$, y a todas las autoridades religiosas y civiles, e integrando niveles devocionales y diversiones risibles, prácticas religiosas y exhibiciones grotescas, presentándose como una verdadera síntesis de lo festivo.

Las celebraciones de todo tipo, entre ellas las mentadas fiestas hagiográficas, se describen en una serie de textos que resultan material de enorme valor para estudiar numerosos aspectos de la sociedad y la mentalidad barroca, y constituyen una especie de radiografía de la colectividad. Como señala Renales ${ }^{11}$ :

acaban siendo exaltación monárquica más que hagiográfica, diferente del caso español, donde las cosas se hacen quizá más disimuladamente. Ver para este asunto Arellano 2009c.

5 Señala Álvarez Santaló (1995: 163) como un rasgo del espectáculo religioso su «esencialidad totalizadora» en cuanto su mensaje emanaría de una decisión «divina» por encima del «voluntarismo social». Propone diversas variantes funcionales como los espectáculos de homenaje-exaltación, imprecación-negociación, a su vez presentados de forma directa o por intermediación. Todas las variedades se advierten en las celebraciones teresianas (y otras hagiográficas barrocas).

6 Álvarez Santaló 1995: 158-159.

7 Menéndez Peláez 2006: 110.

8 Vega 1622.

9 El motivo de la mujer fuerte (que Calderón llevaría a uno de sus autos sacramentales) es muy reiterado a propósito de Santa Teresa, como era de esperar. Escribe fray Diego de Yepes en su Vida de Santa Teresa que Dios le dio para que llevara a cabo su misión «una alma de varón, robusta, fuerte» (lib. I, cap. I).

${ }_{10}$ Como muy bien apunta Ferrer 2003: 30: «Dada su finalidad sociopolítica, la fiesta se construye por definición como una celebración participativa, pero se trata de una participación extremadamente reglamentada, controlada y jerarquizada por las autoridades».

11 Ver para este tipo de relaciones y libros de fiestas barrocas, entre otros, López Poza 1999; Renales 1991/1993. La cita anterior en ibídem: 60.
En los libros de fiestas aparece la ciudad barroca como protagonista colectivo encargado de distribuir entre sus diversos estamentos representativos la labor de realización y coordinación de los preparativos de una conmemoración que adquiere de este modo una dimensión coral.

\section{CELEBRACIONES TERESIANAS Y EL COMPENDIO DE LAS FIESTAS DE BEATIFICACIÓN}

De gran relieve en el ámbito hispánico son las celebraciones de 1622, para la canonización de Ignacio de Loyola, Francisco Javier, Teresa de Jesús, Felipe Neri y el patrón de Madrid, Isidro, y se beatifica a otro jesuita, Luis Gonzaga, pero durante el Siglo de Oro hay otras ocasiones importantes, como las beatificaciones de San Ignacio (1609) y San Francisco Javier (1619), la beatificación de Santa Teresa (1614), el patronato de la misma Santa - tan polémico(1617), la beatificación de San Isidro (1619), la canonización de Santo Tomás de Villanueva (1658), o la de San Francisco de Borja (1670).

Las relaciones de estos sucesos forman, como se ha dicho, un verdadero género en la producción textual del Barroco $^{12}$, y que permiten examinar las diferentes vertientes de la fiesta, y las varias funciones que señala por ejemplo Díez Borque ${ }^{13}$, de "ostentación, propaganda, exhibición, encaminadas a proporcionar fidelidades» políticas y religiosas, sin que pueda tampoco olvidarse la dimensión espectacular y estética de las exhibiciones descritas por los narradores, que cumplen a menudo encargos de los promotores.

No solo los eventos festivos en sí mismos proponen una determinada interpretación o desempeñan papeles diversos en la persuasión religiosa e ideológica, sino que los textos funcionan también como instrumentos de exégesis, como «un verdadero libreto o guía interpretativa del contenido significativo de las celebraciones». ${ }^{14}$

Manejaré en esta ocasión algunas relaciones de la serie celebrativa teresiana que se sucede desde 1614 (beatificación) hasta 1622 (canonización), pasando por la proclamación del patronato de España de la Santa (1617). ${ }^{15}$

De las fiestas por la beatificación de Teresa, el padre carmelita fray Diego San José recoge numerosas relaciones y datos sobre ellas, en la principal fuente de información, que

12 Ver Infantes 1996. Lope de Vega ofrece unas curiosas disquisiciones sobre el género, repletas de ociosa erudición, en el prólogo a su relación de las fiestas de San Isidro («Entre las diferencias de la historia tienen tan ínfimo lugar las relaciones de las fiestas, que aunque por algunos graves accidentes pudieran entrar en los anales, más les podía convenir por opinión de Afelio el nombre de efemérides o diarios, si bien describiendo el mundo aquel excelente Benes dio este nombre a sus hidrográficas y geográficas descripciones...»). Un repertorio de este género ofrece Alenda y Mira 1903. Sobre la estructura y variaciones posibles de estos textos ver Ledda 1996; Renales 1991/1993.

13 Díez Borque 1986: 11.

14 Renales 1991/1993: 68, con interesantes ejemplos de fiestas hagiográficas valencianas.

15 Citaré abreviadamente. En la bibliografía indico los datos completos. Una advertencia: en algunos relaciones como la de Monforte o fray Diego San José hay foliación doble (como si la relación estuviese dividida en dos partes cada una con su numeración): por abreviar indico página o folio como si solo hubiera una numeración: si el pasaje citado no se halla en la primera sección búsquese en la segunda y viceversa. 
publica en 1615 con el título de Compendio de las solemnes fiestas que en toda España se hicieron en la beatificación de N. M. S. Teresa de Jesús, fundadora de la reformación de Descalzos y Descalzas de N. S. del Carmen.

Acopió fray Diego San José noticias de los ciento dieciséis conventos que tenía la orden, las cuales completa con otras relativas a los "desiertos», es decir, ermitas y casas de retiro en los yermos «en las que más propiamente se cumple con lo principal de nuestro instituto, que es la continua oración, las más parecidas en los ejercicios y observancia a las de nuestros antiguos padres» (fol. 218v). Con distinta extensión refiere las fiestas de Madrid (la más ampliamente descrita), Toledo, Barcelona, Lisboa, Málaga, Sevilla, Zaragoza, Ciudad Real, Lérida, Ocaña, Lucena, Caravaca, Palencia, Tarazona, y otras decenas de lugares. ${ }^{16}$

\section{ESTRUCTURA DE LA FIESTA. EL INICIO. CAMPANAS Y FUEGOS}

En esas diversas relaciones se pone de relieve con nitidez la estructura fundamental de la fiesta hagiográfica ${ }^{17}$ - con rasgos comunes a otros muchos tipos de fiestas-, que mantiene un esquema básico, más o menos desarrollado según la pompa de una ocasión concreta. La mayoría de los elementos se reiteran a largo de las celebraciones: comienzan con repique general de campanas, luminarias y fuegos artificiales, y siguen las procesiones, actos litúrgicos con especial protagonismo de los sermones y el ornato de las iglesias, altares y retablos, certámenes poéticos y exposiciones de emblemas, y diversas modalidades de fiesta y diversión profanas que contribuyen al fasto: juegos de toros y cañas, danzas, encamisadas, mascaradas, juego de la sortija, torneos, estafermos, etc.

Como señala el relator a propósito de las fiestas de Cuenca, Pastrana y otros lugares (Compendio, fol. 82v), nada de extraño tiene esta codificación de la estructura festiva, con reiteración de los mismos elementos:

No es de maravillar que en tantas partes echasen mano de unas mismas cosas, pues lo que hace todo género de fiestas célebres es lo referido en los papeles algunas veces, esto es, alegres repiques de campanas, multiplicadas luces de noche, artificiosas máquinas de fuego, ingeniosas invenciones de pólvora, diestros juegos y regocijos de a caballo, ricos y curiosos atavíos de iglesias, suave concierto y armonía de música, así de buenas y diestras voces como de afinados instrumentos, y el último complemento de todo, que son graves y doctos sermones...

El pasaje constituye una buena formulación de los componentes de las celebraciones hagiográficas, y todos ellos se reiteran constantemente en las de Santa Teresa.

Así, por ejemplo, para celebrar la beatificación los carmelitas madrileños llenaron de luces las puertas, lonjas y compás del convento, regocijando al público asistente con árboles, bombas y fuentes de fuego, galeras, sierpes, ruedas "y otras invenciones de pólvora, que con el gran ruido que las campanas de tantos monasterios y parroquias hacían y la copia de gente que concurría de todas partes, fue en extremo regocijada y solemne» (Compendio, fol. 1v).

16 Ver para esta relación Romera Castillo 1998; Manero 1999 y Cammarata 2004.

17 Ver Martín González 1991.
Pero los fuegos artificiales no se limitaban al anuncio de la fiesta, sino que constituían parte fundamental de su desarrollo, y podían adquirir dimensiones de gran espectáculo, en representaciones alegóricas de trascendencia doctrinal o admirables danzas y batallas luminosas para el placer de la vista. Como apunta Díez Borque ${ }^{18}$ :

Hay una obsesión de luz que es a su vez la quintaesencia de la fugacidad, del decorado ornamental efímero [...] sobre todo los fuegos artificiales en su instantaneidad desbordada de color alcanzan cotas de ingenio, como en esos fuegos en castillo, toros encohetados, peleas de hombres con montantes de fuego y otras tantas y variadas formas de la pirotecnia barroca.

Como ejemplo de los innumerables espectáculos pirotécnicos descritos en las relaciones podría citarse el de Alba de Tormes, lugar privilegiado con la custodia del cuerpo de la beata:

A una con las tinieblas de la noche aparecieron luces artificiales sin número en los puestos de la noche primera, y en el aire [...] aparecieron dos caballeros armados a caballo, a guisa de pelear [...] Comenzaron los fuegos con mayor prisa que la noche precedente a romper y encender el aire con extraña fuerza y porfía, ardían bombas a menudo, quedábanse ruedas y a veces con asombro de los circunstantes combatían los caballeros armados corriendo el uno contra el otro con increíble velocidad: cuando partían de sus puestos iba cada uno hecho un Etna, vomitando fuego por las cabezas, lanzas, colas de los caballos y otras partes y al tiempo de herirse se resolvían al parecer todos en fuego, arrojando gran número de cohetes...(Compendio, fol. 23r)

En La Bañeza una tropa de caballeros (Compendio, fols. 93v-94r) defendían un castillo atacado por un fiero dragón salido de una montaña en compañía de una tropa de faunos con bastones lanzallamas. Todos echaban fuego por todas partes hasta que quedó abrasado, castillo, montaña y sierpe.

Pero los fuegos no solo servían al asombro del público, sino que a menudo constituían arquitecturas simbólicas de valor doctrinal, y se organizaban como escenificaciones alegóricas de la batalla entre el bien y el mal.

\section{EXHIBICIONES ALEGÓRICAS. LA LUCHA DEL BIEN Y EL MAL Y LA EXALTACIÓN DE LAS VIRTUDES DE LOS SANTOS}

La lucha de los caballeros que acabo de mencionar tenía una función sobre todo estética, pero en el mismo espectáculo de Alba se habían preparado cinco figuras de gigantes en un tablado «condenadas al fuego, castigo bien merecido a los sujetos que representaban» (fol. 17v), porque representaban cuatro de los más famosos heresiarcas contemporáneos, "con el traje de sus naciones» y la quinta «el padre de todos, Satanás, de horrible y artificiosa compostura» (fol. $18 \mathrm{r}$ ), que por medio de alambres y cordeles secretos movía la cabeza, sacudía la cola y tendía unas grandes alas de murciélago, haciendo ademanes de vuelo con movimientos que pasmaban al vulgo y a los entendidos. Enfrente de este tablado de las figuras diabólicas estaba la santa madre Teresa dispuesta para arrojar rayos de fuego que debían incendiar a los gigantes y al demonio, «maravilloso jeroglífico del va-

\footnotetext{
18 Díez Borque 1986: 21.
} 
lor y la fuerza de sus oraciones, del celo de nuestra santa fe y propagación del santo evangelio, deseos que siempre ardían dentro de su pecho» (fol. 23v). La demostración simbólica la estropeó en esta ocasión un gamberro «atrevido, mal considerado e impaciente incendiario» (fol. 23r), como lo llama la relación, que antes de tiempo prendió fuego al diablo, de cuya cabeza estalló una gruesa bomba que produjo una lluvia de cohetes voladores que abrasó a los herejes, anulando el maravilloso jeroglífico que se había diseñado para la fiesta.

Este tipo de enfrentamientos ígneos de valor alegórico es habitual. En las celebraciones de Barcelona (Compendio, fol. 66v-67r) se dispuso frontero de la iglesia un castillo embutido de tiros, cohetes y otras máquinas de pólvora y al otro lado una nave con no menos artificios de pólvora en figuras humanas que representaban los herejes y apóstatas. En otro lugar se veía un enorme cocodrilo natural traído de Alejandría "lleno también de cosas de pólvora». En su momento apareció por el lado de la playa una hermosa nave toda iluminada con hachas blancas, que llevaba en el castillete de popa una imagen de la beata Teresa, con los hábitos cubiertos de resplandecientes joyas y piedras preciosas, en la mano derecha una pluma dorada y en la izquierda un libro. Dentro de la nave iban ocho niños vestidos de carmelitas y otros cuatros que representaban las virtudes cardinales. Delante de la nave iba un carro triunfal tirado por ocho caballos, con mucha música y cantos. La nave de Teresa se acercó al castillo y nave de los herejes y de improviso el cocodrilo empezó a echar llamaradas de fuego y a volar con unas alas artificiales. Estuvo un cuarto de hora echando fuego por todas sus partes, hasta que la nave de Teresa a su vez lanzó una bomba que incendió al castillo, y luego infinitos cohetes voladores contra la nave herética y «atronaban la ciudad pues de una vez salieron más de dos mil juntos». Al cabo fueron destruidos los perversos y «nuestra santa madre quedó hermosísima y gloriosa señora del campo estándose toda la gente quita de rodillas y derramando lágrimas de devoción».

En las fiestas de Salamanca por la canonización se reservó para la quema mayor, un ídolo de Baal, dios fabuloso de los sidonios (Relación de las solemnes... 1623: 38). ${ }^{19}$ Por la descripción se trataba de un ídolo semejante a otras figuras de demonios, con alas, pies y manos articulados, que se hizo cenizas tras un gran estallido.

Como he señalado en otro lugar ${ }^{20}$ la idolatría y herejía se constituyen en los más asiduos compañeros del demonio. Habitualmente cabalgan monturas monstruosas dragones, o hidras, que son elementos esenciales de esta imaginería - o se asocian a otros animales de diverso valor simbólico. Hay dragones en un castillo de Tarragona, en las fiestas por la beatificación de Teresa. ${ }^{21}$

El enfrentamiento de la ciudad de Dios con el mundo diabólico se ejemplifica admirablemente en la gran construcción de las dos ciudades, Babilonia y la Jerusalén celestial $^{22}$, que las monjas descalzas de Salamanca prepararan

19 Relación de las solemnes fiestas que se hicieron en Salamanca a la canonización de Santa Teresa. 1623.

20 Arellano 2009a.

21 Relación de las fiestas que en la ciudad de Tarragona se hicieron...1615: fol. 92r.

22 Para este motivo ver Arellano 2013. para celebrar la beatificación (Manrique de Luján 1615: 85-86). ${ }^{23}$

La polaridad de ambas ciudades, arranca del Apocalipsis, donde se describe la bestia escarlata de siete cabezas montada por la gran prostituta que lleva la copa de las abominaciones: es "La gran Babilonia, la madre de las rameras y de las abominaciones». Esta Babilonia está destinada a la destrucción junto con todos sus ejércitos terrenales. Tras su caída, el narrador de las visiones ve «un cielo nuevo y una tierra nueva» y la ciudad santa de Jerusalén que baja resplandeciente del cielo.

Las monjas quisieron fabricar una ciudad encima de la torre salmantina de la puerta de Villamayor, ciudad figura de la grande Babilonia. En ella instalaron tres figuras simbólicas de los enemigos del hombre, el Mundo, el Demonio y la Carne «que son la emperatriz y emperadores de los mundanos». En particular resultaba ferocísima la figura del demonio, que meneaba cabeza, garras, dando puñadas al aire, amenazando con un dedo en alto a los espectadores, tirando puntapiés y agitando las alas y la cola como un fiero dragón. Estaba pintado muy al vivo de sapos, lagartos y culebras. El Mundo era un gigante bizarro con galas y plumajes y la Carne era una dama con lujosos vestidos, compuesta con todo el donaire y gala «que en la más desvanecida mujercilla se pudiera pedir».

En contraposición de esta ciudad infame se trazó a la entrada del convento de las monjas descalzas otra hermosa, sobre un arco triunfal con tres cuerpos, en los que se veía a Teresa en medio de Cristo y de la Virgen, que le ponían coronas. Toda la celeste Jerusalén estaba llena de cuerpos de santos, flores y rosas.

La idea era que la santa lanzara un rayo en lo más vivo de los regocijos pirotécnicos para abrasar a la soberbia Babilonia, "quedando victoriosa y triunfante la celestial» (Manrique de Luján 1615: 87), pero la lluvia impidió el efecto. Donde sí pudo llevarse a cabo una traza semejante fue en Mataró (Compendio, fols. 157v-158r), en cuya celebración se construyeron tres tablados: en uno estaba una talla de la santa de rodillas delante de un Cristo, con un ángel al lado que le daba tres saetas. En el segundo una dama muy bien adornada y el tercero un gigante disforme y en el aire un horrible demonio que amenazaba tragarse a la santa, la cual tomó las saetas que le ofrecía el ángel y las tiró a los tres enemigos que tenía enfrente, que representaban el Mundo, el Demonio y la Carne. Los tres se encendieron en vivas llamas, quedando solo un obelisco del que salió un ángel que estaba dentro y traía corona y palma para darla a la santa.

En estos y otros muchos casos que no puedo comentar aquí se evidencia la función didáctica que se encomienda a estas puesta en escena: probablemente este era el objetivo principal para los religiosos - la predicación visual de las virtudes de la santa y su victoria sobre el pecado y la herejíapero en la percepción de las masas populares seguramente el asombro por los admirables espectáculos de luz y sonido, los muñecos articulados, los mecanismos ingeniosos, la música, la luz y las explosiones fueran la atracción principal de esta parte de la fiesta.

23 La misma construcción simbólica de las dos ciudades se hizo en la fiesta granadina por la beatificación de Ignacio de Loyola (Relación de la fiesta que en la beatificación del B. P. Ignacio, fundador de la Compañía de Jesús, hizo su colegio de la ciudad de Granada...1610). 


\section{LAS PROCESIONES Y SUS CONSTELACIONES ALEGÓRICAS}

Las procesiones constituyen el modo más esencial de participación colectiva - como actores o espectadores - en la fiesta, a la vez que suponen el reforzamiento identitario de una sociedad articulada en estratos bien definidos que comparten mayoritariamente una determinada visión política y religiosa. ${ }^{24}$

La participación general en la fiesta se organiza en estratos bien definidos, con la nobleza y el clero a la cabeza. Monforte describe una de las procesiones en las canonizaciones de 1622 (Monforte, fols. 34r y ss.), que puede servir de modelo arquetípico:

Daban principio un gran número de pendones; seguíanse las cruces de los lugares, que fueron muchas, acompañadas cada una de su ayuntamiento; luego las de las parroquias de Madrid. Seguíanse luego todas las religiones por su orden con su cruz, preste, diácono, y subdiácono. [...] Los santos iban por el mismo orden que tuvieron en su canonización. Llevaban el primero a San Felipe Neri cuatro sacerdotes con sus casullas. Siguiose el estandarte de Santa Teresa, que llevaba el padre General de los Descalzos, y luego la santa madre. El estandarte de San Francisco Javier quisieron honrar aquel día los señores de Navarra. Lleváronlo a veces el condestable de Navarra don Fernando de Toledo, hijo del duque de Alba, el marqués de la Hinojosa, Virrey de Navarra, el vizconde Zolina, señor de la casa de Javierre, y sobrino del santo. Venía luego el santo en hombros de sus religiosos. El estandarte de San Ignacio llevaron los señores de Guipúzcoa, que con singular piedad, devoción, y magnificencia se han señalado en celebrar las fiestas de los santos.[...] Comenzaba desde aquí la clerecía, no solo de las parroquias, sino de todo Madrid, con que llegó a un número muy grande. [...] Daban fin la capilla real, y últimamente a lo eclesiástico, el señor don Enrique Pimentel, obispo de Valladolid, vestido de pontifical; detrás los Consejos con el orden que suelen en semejantes ocasiones.

De las específicamente teresianas se puede destacar la procesión del 24 de agosto de 1614 en Ávila (Compendio, fol. $4 \mathrm{v}$ ), que se abría con más de cien religiosos. Llevaban una imagen de la santa, muy adornada de joyas y flores, junto a otra imagen pintada en un estandarte de tafetán blanco con adornos de oro y seda. En el reverso del estandarte figuraba la insignia de la Virgen del Carmen, con muchos santos y santas de la Orden. Nobles y caballeros, con cirios de cera blanca acompañaban a la beata por calles bien aderezadas en las que había de trecho en trecho altares curiosamente adornados.

En el diseño de las procesiones se integran nuevamente alegorías, carros triunfales abundantes en emblemas, y todo tipo de elementos simbólicos, como los planetas, signos del zodiaco, virtudes, vicios, enemigos del hombre, artes liberales, ciudades, etc. Resulta imposible describir con detalle algunos de los programas iconográficos y simbólicos de las principales procesiones que con pompa extraordinaria exhibieron el triunfo de los santos. Frecuentes son las alegorías de las cuatro partes del mundo. ${ }^{25}$

Miguel de León (Madrid, 1622) apunta brevemente que de los doce carros triunfales que sacaron los padres de la

24 Remito para otras observaciones sobre la estructura procesional, su ritual y objetivos a García Bernal, Tercera Parte «El espectáculo de la excelencia: procesiones y cortejos» (2006: 313-421).

25 Ver Arellano 2003.
Compañía los cuatro primeros llevan las cuatro partes del mundo, acompañadas de estudiantes a caballo con broqueles en los que figuraban los reinos y provincias más principales, y que en el claustro de los carmelitas se dispuso una admirable fuente cuatro de cuyos caños iban a cuatro figuras muy grandes «que eran África, Asia, Europa y América, aludiendo al riego de la doctrina que de la santa [Santa Teresa] habían recibido».

La relación de Monforte es mucho más precisa y rica en detalles, y procede a una meticulosa y muy extensa descripción de los carros y sus alegorías de las cuatro partes del mundo en el triunfo de San Ignacio y San Francisco, pero útil para cualquier ocurrencia de estas personificaciones alegóricas:

Así en este triunfo mundo y cielo, uno por conquistado, el otro por bien servido salen a celebrarlo, sacando cada uno lo que mejor tiene; el mundo saca sus cuatro partes: América, Asia, África y Europa, en cuatro hermosos carros (cuya pintura irá después). A cada parte, acompañan sus moradores lo más de gala que pueden; el cielo saca lo más lucido que tiene y por eso saca sus planetas, signos y astros. [...] Dio principio al paseo un juego de trompetas y atabales, estampado en las banderas de las trompetas y cubiertas de los atabales un Jesús en águilas imperiales. [...] Comenzando la tierra el paseo, ofreció el primer lugar a América, delante de cuyo carro iban veinticuatro de sus indios, con propios trajes; delante de cada cuadrilla iba un paje armado, llevaba en la rodela las armas de aquella nación. Salieron en primer lugar los araucanos, convertida su ferocidad en gala con jaquetilla de tela, pasamano de plata, jubón y calzones anchos de tela de plata [...] Seguíase América en un bizarro carro, [...] Estaba encima del trono un caimán, o cocodrilo de plata muy al natural, y encima América vestida de vaquero de damasco azul con pasamanos de plata [...]

A la segunda parte del mundo que es Asia, acompañaban también sus moradores, y en primer lugar los persianos [...] Daba fin Asia en un airoso carro que desde un plano coronado de verjas de jaspe y oro, daba paso por cinco gradas bordadas de mil colores a un trono sobre quien estaba echada una abada, animal propio de aquella tierra, y encima Asia [...] Daban principio a la tercera parte, que es África los moros africanos con vaqueros de tabí de oro y plata, azul y encarnado [...] dábale a África una media luna (propias armas suyas) un vistoso carro, que en el testero levantaba su trono [...] y en él un elefante de pasta muy bien acabado [...] estaba África sentada sobre el elefante [...] A Europa que iba en último lugar de las cuatro partes del mundo, le acompañaban en primero los turcos con vaqueros de tela de oro y plata [...] Echó el sello a sus demostraciones con sacar la última a Europa en un vistoso carro, cuyo plano cercado de barandillas de plata, y listas azules, daba paso por cuatro gradas ceñidas a los lados, con dos delfines muy vivos a un trono cogido en medio de dos pilastras, $y$ dos carteles que remataban en cuatro bolillas.

Encontraremos esta alegoría - con figuras probablemente inspiradas en la Iconología de Cesare Ripa-, con diversas variaciones, una muy interesante, en las fuentes del convento de Alba y de Salamanca, que comentaré más abajo.

\section{LOS CARTELES (PROGRAMA DE FIESTAS). JUSTAS Y CERTÁMENES POÉTICOS. OTROS ASPECTOS LITERARIOS}

Todas las actividades que se van a suceder durante los días determinados de las fiestas se suelen publicar en los carteles generales completados por los particulares de ciertos eventos 
como certámenes o justas caballerescas. Punto esencial de estos carteles son los requisitos y premios de las imprescindibles justas o certámenes poéticos en loor de los santos.

En el cartel que publican los carmelitas descalzos del colegio de San Hermenegildo de Madrid para las fiestas teresianas de beatificación, se subdivide el certamen poético en ocho pruebas: la primera consiste en hacer un epigrama latino en seis dísticos a la ciencia infusa de Santa Teresa, con premios de un agnus de oro, otro de cristal y las obras de fray Luis de Granada; la segunda propone un himno latino de menos de veinticuatro versos pintando las cosas más excelentes de la santa; el tercer certamen ofrece un jarro de plata - primer premio-, ocho varas de chamelote - segundo- y unas medias de seda - tercero- a quien «con más gracia, erudición y elegante estilo, guardando el rigor lírico, hiciere una canción castellana en la medida de aquella de Garcilaso que comienza El dulce lamentar de dos pastores, a los divinos éxtasis que tuvo nuestra santa madre», etc.

Invitado especial en estas fiestas fue Lope de Vega, que leyó el cartel, después de hacer él mismo una intervención en verso, que a todos pareció brevísima «según la eminencia con que lo hizo, la gravedad y gracia que tuvo en el decir, la propiedad y espíritu en sus acciones, la dulzura y eficacia en su razonamiento, la autoridad y devoción del asunto, la moción y ternura que causaba en los circunstantes». La «Oración» lopiana (Compendio, fols. 4v. y ss.) es el poema «Platón muriendo, noble, heroico, ilustre, / grave y docto senado, dijo alegre», que canta las excelencias de Santa Teresa como ejemplo de mujer admirable, refutando las opiniones (entre ellas la de Platón) de considerar a la mujer ser inferior al hombre.

El Compendio de las fiestas de Santa Teresa recoge, además del de Lope, otros muchos poemas: composiciones de Vicente Espinel (himno "O Virgo mater virginum») y Cervantes («Virgen fecunda, madre venturosa»), entre producciones de religiosos de poca nombradía poética y otros aficionados. Alguno se preocupa tanto por ajustarse a las leyes del certamen que las siguen al pie de la letra: si el octavo certamen de estos festejos pedía una canción castellana en la medida de El dulce lamentar de dos pastores, de Garcilaso, el Dr. Campezo salió del paso cambiando algunas palabras del modelo, que quedó así:

El dulce lamentar de los pastores

Cristo y Elías, cada cual celoso

he de cantar sus quejas imitando,

cuyas ovejas al cantar sabroso

estaban muy atentas los amores

casi de sí olvidadas, escuchando.

Tú que ganaste obrando

un nombre en todo el mundo

y un grado sin segundo

agora de tu esposo estés al lado

gozando como gozas nuevo estado,

Teresa, en esas glorias que reparte

tu esposo regalado

aunque gusta en amor eternizarte...

Monforte (fol. 11v) describe en las canonizaciones una Justa de los planetas, en la que a Venus le corresponde las alabanzas de Santa Teresa:

ha de cantar la gloria de Teresa y convidar a que alaben un corazón tan dado todo a Dios, que mereció que un ángel se le abrasase con fuego divino. Quien en seis décimas más dulcemente cantare este favor divino tendrá por premio una escribanía de ébano y marfil. Vale veinticinco ducados. El segundo, una firmeza de oro de santa Teresa, de valor de quince ducados. El tercero, un breviario de cámara entera, muy bien encuadernado. Vale diez ducados.

Y la diosa se confesó vencida por la santa (fol. 89r-v):

Venus entre prisiones y cadenas, confesándose por vencida del singular valor de la ilustre virgen santa Teresa de Jesús, y aunque por ser cautiva podía extrañar el canto, quiso ser otra vez vencida de las grandezas de Teresa, mostrando cómo no hay quien pueda dar alcance a sus heroicas virtudes. Cantó en seis décimas el haberle traspasado un serafín el corazón. Juzgáronse por las mejores las de don Bernardo Arias de Toledo.

DÉcimas a la madre SANTA TeRESA de don BERnARdo ARIAS DE TOLEDO

Enternecida de amor hasta a Dios levanta el vuelo Teresa, que admira el cielo su santidad, su valor: de Dios es alba y candor, y así hasta Dios se levanta la rica, la fértil planta de Elías y de Eliseo, dando al Carmelo trofeo casta Virgen, Madre santa. $[\ldots]$

Un Querubín abrasado, que incendios de amor publica, a su corazón aplica, rendido y enamorado, dardo que la ha traspasado el corazón que ella ofrece a Dios, porque la parece víctima para su esposo: y así le ofrece gozoso, se deshace y se enternece.

Etc.

Un rasgo general de estas composiciones es su exhibicionismo ingenioso que se manifiesta en textos raros y curiosos, de rimas forzadas, de cabo roto, en varias lenguas o macarrónicos, con afición a los géneros dificultosos como enigmas, emblemas y jeroglíficos... Hubo, escribe fray Diego San José en el Compendio (fol. 3r), «bellísimos epigramas latinos, himnos, jeroglíficos y emblemas curiosamente pintados y escritos, con otras muchas poesía castellanas en todo género de versos».

El ingenio se desliza en ocasiones a la comicidad. En el certamen de Madrid participó un tal «González el estudiante», con diversas poesías jocosas: si Santa Teresa, dice, se pasaba un día sin comer, en sus éxtasis místicos, el estudiante se pasa sin comer muchos días, por muerto de hambre, cuyo remedio implora de la santa:

Oíd a vuestro hambriento Garcilaso que hoy ayuna el traspaso.

Ya de comer se olvida por falta de comida que no por buena gana, que le sobra; ya el gusto no es sentido ni en él obra. Solo en mí come sarna estudiantesca... (fol. 60v) 
Y a la misma pluma en las mismas fiestas se debe este curioso soneto sonetil con los consonantes forzosos que pide el séptimo certamen en filo, alba, malva, Nilo, estilo, salva, calva, etc.:

¿Qué piedra de amolar me dará un filo que pierdo en seso de la noche al alba por saber las virtudes de la malva y al cuarto verso acomodar el Nilo? Ya mi musa con bueno o mal estilo deste primer cuarteto queda salva, mas ¿cómo agora encajaré la calva y en el octavo verso a San Cirilo? Cuartetos fuera. Los tercetos se armen. Mas ¿qué diré de vos, si tantos sabios os suben a tan altas jeraquías? Teresa, Dios os hizo para el Carmen; yo pongo en vuestros pies mis rudos labios: el soneto acabé, gracias a Elías. (fol. 79r)

En Pastrana se presentaron poemas en jerga vizcaína, sayagués o guineo, como este soneto:

¿Non zabe vosansé, ziñolo Andleya como anqueyan Teleza que en Sibiya en Gávila plimelo y en Casiya fondon tanto lan casa e monaseya? Glan fiesa selen fase ioh, cosan beya! con tanto luminayo e chilumbiya...(Compendio, fol. 86v)

Todos los certámenes tienen una sección de jeroglíficos y emblemas, acompañados de dibujos, género que prolifera también en las arquitecturas efímeras, carros triunfales o altares.

El sexto certamen de la beatificación de Santa Teresa es de emblemas y jeroglíficos». Un ejemplo: se pinta un sol cuyos rayos reflejados en un cristal incendian un monte, con la letra:

Por el cristal de Teresa

el sol Cristo unido pasa

con que el Carmelo se abrasa (fol. 70v)

Don Gonzalo de Ayala, en las fiestas de canonización, presentó un emblema teresiano del que aporta la explicación (Monforte, fol. 101v):

Manda Dios al hombre no coma del árbol de la ciencia; come, destiérrale del paraíso, y pone un querubín por guarda, para que no le deje tocar al árbol de la vida.

Pintose un querubín en un huerto entre dos árboles con dos inscripciones que dicen: Vita, scientia: un rostro de un hombre que mira entre los árboles y el querubín con esta letra: comedat et vivat.

\section{Castellana:}

Con los misteriosos ramos

de la ciencia y de la vida

nuevo querubín convida.

Significa el querubín a santa Teresa, por ser los vírgenes ángeles en la tierra y la santa de superior jerarquía, por el amor encendido y conocimiento de las cosas divinas; los ramos, los libros de mística Teología que escribió, nacidos en el mismo paraíso; Cristo, que lo es todo juntamente.

No faltan las versiones emblemáticas burlescas en forma de parodia, otra vez debidas al estudiante González (Compendio, fol. 75v):
Píntese una ratonera armada y un virote con plumas blancas, con una letra que diga "Arma virumque cano». A un lado se pondrán colgadas tres varas de longaniza y diga la letra latina "Longanimitas». Al otro lado se pintará un papagayo dando voces y diga la letra: «Pontificatus». Después de pintado lo dicho cubríase esta pintura con una manta y un garabito, y la letra española diga:

Aquesta emblema pintada

no la pongan, padres míos,

porque es todo desvaríos

y no significa nada.

Otros componentes literarios o religioso-literarios de la fiesta son los sermones, parte fundamental de las actividades. Normalmente los textos no se incluyen en las relaciones, remitiéndose a volúmenes especiales, pero alguna vez, como en la relación salmantina de beatificación publicada por Manrique Luján se incluyen varios sermones de los padres Pedro de Herrera, Francisco Girón o fray Pedro Cornejo. En las fiestas principales actúan los más famosos predicadores de la época: en la Relación sencilla y fiel de las fiestas que el rey don Felipe IV... hizo al patronato de sus reinos... que dio a la gloriosa virgen Santa Teresa de Jesús (1627) por ejemplo, se recogen meticulosamente dos listas de ocho religiosos cada una (fols. $6 \mathrm{v}$ y ss.) que dieron los sermones en el convento de los frailes y en el de las monjas, entre ellos varios predicadores de su majestad, como fray Francisco de Jesús, fray Cristóbal de Torres, fray Domingo Cano, sin que faltara el famoso Hortesio Paravicino. En las de beatificación madrileñas predicaron «insignes predicadores y maestros», como los padres Florencia, Plácido Tosantos o el mismo Paravicino.

En el cruce de lo literario y espectacular se sitúan las representaciones dramáticas, a menudo comedias hagiográficas que representan escenas de la vida de los santos, sin que falten tampoco las comedias profanas que forman parte de las celebraciones.

Hay numerosas referencias a comedias sobre Santa Teresa representadas en estas fiestas, unas a cargo de comediantes profesionales, y otras a cargo de aficionados de la localidad. ${ }^{26}$ Para la beatificación en Ávila se hicieron dos comedias, una de la santa y otra sin especificar el asunto; en Toledo se hicieron varias comedias; otra en Burgos, de la niñez de la santa, en la que "lo representantes fueron niños de a doce años, hijos de caballeros de esta ciudad» (fol. 63r); en Pamplona «hicieron unos estudiantes [...] una comedia de nuestra santa madre harto buena» (fol. 89r); en Talavera (fol. 165r) hidalgos y caballeros hicieron una comedia de la vida y muchos milagros de nuestra santa madre», y la representaron en la iglesia y en otras partes de la villa; otras hubo en Valladolid, Toro, Corella, Medina del Campo, Ciudad Real, Vélez Málaga, etc.

En Alba la relación menciona al autor Morales (¿Alonso o Pedro?), que representó una comedia de San Francisco y otra de la beata Teresa; además en diversos días en la misma población se pusieron en escena El gran duque de Moscovia de Lope de Vega; La serrana de la Vera de Vélez de Guevara; El esclavo del demonio de Mira de Amescua; la anónima Alerta, no os descuidéis.

26 Ver el cómodo resumen de Romera Castillo 1998: 271-275, donde localiza las menciones de estas comedias en el Compendio. 
En las fiestas teresianas de Lerma, la propia Ana de Austria, reina de Francia, "los príncipes y algunas damas representaron una comedia en palacio a puerta abierta para que todos los que pudiesen caber gozasen de ella» (Compendio, 142r).

\section{LOS ESPACIOS INTERIORES Y EXTERIORES. EL ORNATO}

Los actos festivos se despliegan en escenarios múltiples que integran los interiores sacros, sus aledaños y las calles y plazas de la ciudad. El primer tipo acoge los principales actos religiosos y se suele adornar con proliferación de colgaduras, tapices y pinturas, esculturas y reliquias, cirios y flores, con una riqueza exuberante. Dentro y fuera de las iglesias se acumulan gradas, obeliscos, altares y retablos que soportan damascos, sedas, pedrerías, labores de plata, insignias de los santos y de los reyes, emblemas y jeroglíficos, tarjas con inscripciones, además de las imágenes de los santos, de bulto o pintadas... En la iglesia de las descalzas de Alba proliferaban las colgaduras bordadas de grotescos, corredores de madera con altares aderezados con ricos ornamentos y cuadros de episodios de la vida de Santa Teresa, cada uno con textos explicativos, tapicerías con las tentaciones de San Antonio, copia del Bosco, y lujosos reposteros. La relación de Burgos dedica un capítulo completo al «Ornato de la iglesia» (Compendio, fols. 57v-62r), donde describe en varias páginas los candeleros, colgaduras, reliquias, ramilletes, altares de ricos frontales, etc.

Los reyes y los nobles contribuyen prestando reposteros, joyas y vestidos, tanto para las arquitecturas como para las imágenes. En las fiestas del patronato teresiano el rey y Olivares fueron los principales impulsores, y es el rey quien corre con todos los gastos de la fiesta, prestando para entoldar la iglesia de los carmelitas los famosos paños de Túnez ${ }^{27}$, que también fueron a la iglesia de San Roque de Lisboa en las canonizaciones de San Ignacio y San Francisco Javier. Las joyas, por valor de doscientos mil ducados, que adornaban una imagen de la santa, las prestó la infanta doña María, reina de Hungría (Madrid, Relación sencilla y fiel, 1627, fol. 8r).

Sin espacio para examinar en detalle estos complejos bastará tomar como guía significativa los altares de las fiestas madrileñas de canonización de 1622, descritos por Lope, pero sobre todo por Monforte, que dejan clara la fusión de aspectos, la presencia de la simbología religiosa, la tradición de los emblemas, y los mecanismos de personificación alegórica, todos los cuales se hallan igualmente en las series procesionales. Extraigo algunos pasajes relativos a Santa Teresa en la relación de Monforte (fols. $18 \mathrm{v}$ y ss.):

Jardín de la Plaza de la Cebada.

Apenas se entraba en la plaza de la Cebada, cuando airosas se veían volar por ese medio dos pirámides dedicadas a la Santa virgen Teresa de Jesús [...] arquitectura ingeniosa, hieroglíficos y figuras [...] Bordaron su plano todo género de flores, que salpicadas de las fuentes, que a cada paso bullían, gozaban todo el día del aljófar de que las demás tanto se glorían por la mañana, y porque a los sueltos pájaros no les faltase

27 Esta serie de tapices denominada «La conquista de Túnez» obra de Bermeyen y Pannemaker, encargada en 1535 por María de Hungría fue elemento importante en la configuración de la imagen triunfal de Carlos V, y se usa en varias ocasiones como las citadas fiestas como elemento ornamental y significativo de la gloria de los Austria. donde gorjear con sus harpados picos, se vieron árboles trasplantados, que los estaban convidando con sus verdes ramas.

Altar y recibimiento del rector de la Latina.

En el arco de la mano izquierda estaba sobre otro trono santa Teresa, hincada de rodillas en éxtasis, la mano derecha en el pecho y la otra abierta y extendido el brazo, su vestido estaba bordado de una escaramuza de eses de plata, y unas estrellas de oro con un rayo grande por la ilustración que tuvo en la oración. A su lado estaba un ángel con una tunicela de tabi blanco, y encima un roquete corto de velillo encarnado prensado, manga ancha, puños y cuello abierto, con mucha argentería, en la frente un apretador de diamantes, y en la mano derecha un dardo, en significación de haberle traspasado el corazón. Cubría el altar un dosel bordado, muy grande; los frontales, todos uniformes y muy ricos, campo blanco, bordados de rasos de colores y perfiles de oro; las gradas ocupaban vistosos relicarios, cuerpos ramilleteros, perfumadores y muchos candeleros, en particular había en la tabla del altar unos ramilletes de canutillo de vidrio y oro escarchado, y ramos de lentejuelas de plata, que lucieron mucho; fue sin duda de lo muy bueno que salió, porque ni en adorno ni en vestido de santos, riqueza y curiosidad cedía a ninguno, y en muchas le aventajó; tuvo de ordinario un juego de chirimías, principalmente para el recibo de la procesión.

Altar de los padres Mínimos de Nuestra Señora de la Vitoria

La castidad, que era la última, representaba a la santa virgen Teresa de Jesús, tenía un manojo de azucenas en la mano; la letra latina «Eras etiam virtuti castitas adiuncta».

El que le ciñe la inmortal corona (Virgen Teresa) que de Dios alcanzas, No de marchitas flores te corona, Sino de adoraciones y alabanzas; Tú santa, tú magnánima perdona Si añado breve gloria a tus bonanzas, Que ya a tu castidad son altos dones, Cándidos sacrificios y oblaciones.

Todos los lados de altar, y los claros que había (necesarios para la arquitectura) cubrían vistosos paños bordados y otras telas ricas. El pavimento lleno de alfombras, esmaltadas con variedad de flores. Hubo siempre menestriles, que lo más del tiempo dieron música, principalmente cuando pasaba la procesión.

No hay espacio para reproducir aquí las numerosas descripciones ponderativas de la organización del ornato y los espacios de las fiestas. Como ejemplo significativo recordaré para terminar este apartado solo algunos detalles de la artificiosa fuente levantada en el patio de las descalzas de Alba, que reúne los simbolismos arquitectónicos con los juegos de agua y la técnica de los emblemas (fols. 19v-22v). La fuente tenía en los cuatro ángulos cuatro pirámides terminadas en bolas - símbolo de perfección-, y cuatro cubos a modo de pedestales de cuatro figuras que representaban las cuatro partes del Mundo con sus insignias y atributos (América con tocado de plumas, Europa con corona imperial, África de color negro, Asia con vestiduras orientales). En un segundo cuerpo y sobre dos repisas se sustentaban dos niños de buena escultura, uno con las armas del Duque de Alba y el otro con el escudo de la Orden del Carmen, todo enriquecido con molduras y figuras geométricas, y llenos los espacios de poesías. En el último cuerpo hacía asiento 
una peana con la imagen de Teresa, de tamaño natural, con una pluma en la mano derecha y un libro en la izquierda. Del libro brotaban llamas de fuego (símbolo de su ardiente fe) mediante un mecanismo que intrigaba «a los buenos ingenios que allí había». De toda esta máquina, a su tiempo, brotaban múltiples caños de agua que iban a llenar unos vasos que tenían las partes del mundo, de manera que la luz y agua que brotaban de la santa iban a vivificar al mundo entero. Varias quintillas en las estatuas explicaban a los menos ingeniosos el sentido simbólico de estos complejos jeroglíficos, por ejemplo:

El Asia, la mayor parte de la tierra y su teatro, del agua y luz que reparte Teresa a sus partes cuatro recibe alegre su parte. $[\ldots]$ Europa, provincia rara, pues encierra en sus distritos Ávila, mi patria cara, reciba de mis escritos la luz pura y agua clara.

La misma fuente se describe minuciosamente con nuevos detalles en la relación de Manrique de Luján (1615: 2833): «Párrafo primero en que se describe una ingeniosísima fuente que estaba en el claustro de los padres descalzos carmelitas».

\section{LA DIVERSIÓN}

Aliados de las dimensiones doctrinales no pueden faltar en las fiestas barrocas las vertientes del ludus y la admiratio. Enseñanza y diversión van juntas, sirva esta a aquella o tenga valor autónomo. ${ }^{28}$

No entraré en el comentario del entretenimiento que supone la espectacularidad general del boato de vestiduras, máquinas, luminarias y músicas. Las tópicas ponderaciones de lo novedoso y extraordinario de los fuegos artificiales son buen índice del gusto con que el público los recibía, igual que las máquinas y animales fingidos o verdaderos. Las fiestas de beatificación en Corella - Navarra ${ }^{29}$ - no son, naturalmente, las más ostentosas de las descritas por el P. San José, pero reflejan arquetípicamente la función de lo lúdico en un ámbito local, que no dispone de los medios capitalinos, pero que se esfuerza en desarrollar con el mayor empeño la estructura y objetivos de la fiesta hagiográfica.

Se adornó la iglesia de los carmelitas como era costumbre, con colgaduras, cuadros, jeroglíficos y versos, en vistosas tarjetas, con gran afluencia de gente del pueblo y de los lugares cercanos. Una imagen de la beata Teresa exhibía ricas vestiduras de damasco blanco, con orla de oro, cadenas de lo mismo y cincuenta piezas grandes esmaltadas. A la espalda de la imagen «había un escudo grande de la orden, formados sus campos, monte, estrellas, cruz y corona de muy finos diamantes, acompañados de perlas y labor de gusanillo» (fol. $116 r$ ), sin contar otros adornos de rubíes, esmeraldas, perlas, topacios y piedras de mucho valor, amén de numerosas

28 Ver Arellano 2009a, donde se comentan otros elementos de estas y otras fiestas. Recojo algunas líneas de este trabajo anterior.

${ }_{29}$ Ver para las fiestas teresianas navarras Elizalde 1982 piezas de oro en el velo y diadema, y un rico pectoral con «un buen pedazo del lignum crucis»: "toda la santa finalmente era un agregado bien dispuesto de cosas de grande precio», lo mismo que las andas, o el adorno del altar.

Después de cantar los oficios salió una danza muy curiosa (que no se describe) y se representó una comedia (de la que no se dan más detalles). Por la noche hubo grande exhibición pirotécnica, una encamisada de caballeros y personas principales, y una batería de fuegos que se dieron las torres de las dos parroquias de la villa (el Rosario y San Miguel), con otras muchas cosas que se dejan de contar.

Al día siguiente, domingo, continúan las fiestas, con misa solemne, procesión y danzas de cohetería, sortija y otras invenciones, entre ellas una lucha entre veinticuatro demonios horribles - con sus garfios y otras insignias espantables que despedían mucho fuego hediondo-, y un ángel sobre un caballo blanco en los aledaños de la iglesia carmelita, de cuya puerta salió luego un carro triunfal muy vistoso, enramado de flores y con muchas chirimías y vihuelas: en lo alto del carro venía un niño vestido de monja descalza, que representaba a Santa Teresa. Los demonios vencidos iban ahora encadenados rodeando al carro, llenos de grillos y cormas, pero - es de suponer - libres de la estupenda fetidez que antes hacía que «parecieran ser lo que representaban» dice el cronista que hubo:

Una danza que por sus fuegos y figuras ponía admiración y espanto. Esta fue de 24 hombres en figuras de demonios horribles con sus garfios y otras insignias espantables, despidiendo mucho fuego de sí, y tan hediondo, que parecían ser lo que representaban. Andaban desconcertados, discurriendo por entre los álamos y árboles desta calle, dando espantosos bramidos. Estando en esto salió e improviso un angel muy hermoso por detrás de la iglesia en un caballo blanco, con sus alas tendidas y espada en la mano, y peleó un gran rato con ellos...

Hubo también estafermo (una especie de maniquí giratorio que se golpeaba con una lanza y había que evitar el golpe que daba al moverse):

Se habían preparado en la calle muchos tablados y la gente que no cabía en ellos se subía a las ramas de los árboles, especialmente muchachos, y alguna vez se desgajaban las ramas y caían a docenas sirviendo de risa en la fiesta, sin que ninguno recibiese daño. Acabado el estafermo corrió la voz de que se habían de correr toros en la plaza y asi muy presto acudieron todos alla. Corrieron siete u ocho y ningun toreador recibió daño

Torneos, encamisadas, danzas, juegos de alcancías, estafermos, juegos de sortija, y otras muchas diversiones se reiteran en todos los casos. Particular potencial jocoso tienen algunas mascaradas ridículas que se insertan en la fiesta. Recordaré solo, por lo relevante de su asunto, las mascaradas quijotescas ${ }^{30}$ de la Universidad de Zaragoza o la de Córdoba en las fiestas de beatificación.

En Zaragoza se vio el triunfo de don Quijote ${ }^{31}$ :

Venía don Quijote de la Mancha, con un traje gracioso, arrogante y pícaro; puntualmente de la manera que en su libro se pinta. Esta figura y otra de Sancho

\footnotetext{
30 Arellano 2005.

31 Ver Egido 1983: 9-78, de donde tomo el texto.
} 
Panza, su criado, que le acompañaba, causaron grande regucijo y entretenimiento; porque a más de que su traje era en extremo gracioso, lo era también la invención que llevaban, fingiendo ser cazadores de demonios que traían allí enjaulados, y como triunfando dellos, habiéndolos cazado a honor de la fiesta de la Santa Madre, y con el favor suyo; y estos se representaban en dos fieras máscaras atadas, cuyas cabezas estaban encerradas en sendas jaulas. Sancho Panza salió con un justillo de pieles de carneros recién muertos, el pelo hacia adentro, de suerte que todo el vestido parecía carne y toda ella hidrópica, porque estaba toda hinchada, como si en extremo lo fuera tanto, que adonde tocaba con el cuento o remate de una lanza de encuentro que en la mano traía, quedaba allí una hondura, que después se iba igualando, como si dentro llevara algunos fuelles; acción que al vulgo causaba extraordinaria risa, como también la causaron los papelillos que con algunos motes daba a las damas, y una información (abono de su justicia) que en razón del premio nos presentaron en unos versos del tenor siguiente: $[\ldots]$

Don Quijote

La Fama con tal estruendo a donde estaba llegó que aun vestir no me dejó. Tan hecho estoy a vencer y con lo que emprendo salgo, que de armas no me valgo. Con mi esfuerzo y robustez a las fiestas de Teresa traigo gente que le pesa. Ya no hay diablos de valor para tentar a los hombres, que con tu nombre no asombres. Penan ellos de tu gloria y tus altas maravillas, que ocupan todas tus sillas. Por hacerte algún servicio, Teresa, estos dos cacé y al punto los enjaulé.

Sancho Panza No estaba con poco gusto cuando mi señor cazaba que él corría y yo emboscaba.

Diablo primero Reniego del cazador que a ver esto me ha traído, pues que mi pena ha crecido con otra gloria mayor.

Diablo segundo Por fuerza habré de llorar, Teresa, en esta ocasión, pues aumentas mi pasión ocupando mi lugar.

En Córdoba se integra en la fiesta la mascarada de los desposorios de don Quijote con Dulcinea ${ }^{32}$ :

Guiábanla las trompetas y atabales a caballo con sus libreas, a quien seguía un ridículo personaje, así por el desaliño de un flaco y despeado jumento en que iba, como por el aderezo de su persona, que era de trapos de colores cosidos con artificio. El traje era aldeano; al hombro llevaba una bandera de un paño de cama azul, tan apolillado y roto como deslucido, y en medio dél un pellejo de cabrito extendido, que mostraba bien su fi-

32 Relación breve de las fiestas que en la ciudad de Córdoba se celebraron a la beatificación de la gloriosa patriarca Santa Teresa de Jesús...1615. gura, con un rótulo por orla, que decía: «Desposorio de don Quijote y su amada Dulcinea». En pos dél iban los demás con graciosas invenciones, de dos en dos, vestidos de pellejos de conejos unos, otros de arambeles bien concertados, otros cubiertos de huevos, y todos en pollinos tan malparados y flacos, que no había alguno que no cojease. Los que más bien lo hacían, y sentaban a veces las ancas en tierra, eran los de un cura y sacristán, cada uno con la insignia de su ministerio. Llevaban sus gualdrapas, y los demás muchas cédulas con dichos graciosos, que repartían a la gente. Sancho Panza tuvo por mejor partido caminar en una burra poco menos redonda con su preñado que el que iba en ella, con serlo tanto como una bola, y de esta manera escudereaba los desposados, que venían los últimos. Don Quijote en un rocín blanco en los huesos, con una calza con las cuchilladas de palma, por botas o borceguíes dos calabacinos huecos y muy largos, por rosas en las ligas dos cebollas, dos tiestos por estribos, pendientes de dos tomizas; sobre la camisa, un coleto vejísimo, y gorra antigua con su cintillo de esparto y algunas cabezas de ajos por camafeos. Doña Dulcinea iba en un pollino con vestido igualmente ridículo, y tal, que el más modesto en llegando estas dos figuras no podía contener la risa.

\section{CONCLUSIONES}

Las fiestas hagiográficas se aparecen, en suma, como un género privilegiado de exploración de las vertientes apologéticas y doctrinales del docere, y a la vez como un muestrario excepcionalmente variado y completo de los elementos del fasto destinados a causar la admiración, y de los componentes cómicos dirigidos a provocar la risa en el espectador.

El análisis de las relaciones de fiestas permite acercarnos a estas complejas manifestaciones que, enmarcadas en la reforma católica tridentina, revelan también la unión de la monarquía y la Iglesia, y exhiben desde el punto de vista estético, un enorme despliegue de medios de expresión desde la iconografía y emblemática al teatro y la poesía, desde los fuegos artificiales a las danzas y pandorgas, desde el sermón a la mascarada grotesca: un verdadero universo de representaciones que pretenden enseñar y entretener, o enseñar entreteniendo, a la vez, naturalmente, que exaltan la figura de los santos, en especial en el caso que me ocupa, la de Santa Teresa, que sería doctora de la Iglesia y patrona de España.

\section{BiBLIOGRAFÍA}

Alenda y Mira, J. 1903. Relaciones de solemnidades y fiestas públicas de España. Madrid: Sucesores de Rivadeneira.

Álvarez Santaló, L. C. 1995. «El espectáculo religioso barroco». Manuscrits 13:157-183.

Arellano, I. 2003. "América en las fiestas jesuitas». Nueva Revista de Filología Hispánica 56: 53-86.

Arellano, I. 2005. Mascaradas quijotescas. Pamplona: GRISO, Pliegos volanderos del GRISO.

Arellano, I. 2009a. «Enseñanza y diversión en fiestas hagiográficas jesuitas», en I. Arellano y R. Rice (eds.), Doctrina y diversión en la cultura española y novohispana: 27-54. Madrid: Iberoamericana.

Arellano, I. 2009b. "Fiestas hagiográficas madrileñas en el Siglo de Oro», en J. M.a Díez Borque, E. Borrego y C. Buezo (eds.), Literatura, política y fiesta en el Madrid de los Siglos de Oro: 195226. Madrid: Visor.

Arellano, I. 2009c. «Vive le roy! El poder y la gloria en fiestas hagiográficas francesas (canonización de San Ignacio y San Francisco 
Javier, 1622)», en I. Arellano, E. Williamson y C. Strosetzk (eds.), Autoridad y poder en el Siglo de Oro: 9-34. Madrid: Iberoamericana.

Arellano, I. 2013. "Corografía mística: Babilonia y Sión en los autos sacramentales de Calderón». Bulletin of Spanish Studies 90: 473-494.

Cammarata, J. 2004. «El espectáculo y la divinidad: la relación de fiestas por la beatificación de Santa Teresa de Jesús», en Actas del XIV Congreso de la Asociación Internacional de Hispanistas, II: 59-66. New York: Juan de la Cuesta.

Díez Borque, J. M. a 1986. «Relaciones de teatro y fiesta en el barroco español», en J. M.a Díez Borque (dir.), Teatro y fiesta en el barroco: 11-40. Barcelona: Serbal.

Egido, A. 1983. «Certámenes poéticos y arte efímero en la Universidad de Zaragoza (siglos XVI y XVII)», en Cinco estudios humanísticos para la Universidad de Zaragoza en su centenario IV: 9-78. Zaragoza: Caja de Ahorros de la Inmaculada.

Elizalde, I. 1982. «Fiestas y certámenes poéticos en Navarra con ocasión de la beatificación de Teresa de Jesús (1614)». Príncipe de Viana 14: 941-950.

Ferrer, T. 2003. "La fiesta en el Siglo de Oro: en los márgenes de la ilusión teatral», en Teatro y fiesta del Siglo de Oro en tierras europeas de los Austrias: 27-37. Madrid: Seacex.

García Bernal, J. J. 2006. El fasto público en la España de los Austrias. Sevilla: Universidad de Sevilla.

Infantes, V. 1996. "¿Qué es una relación?», en M.a C. García de Enterría (ed.), Las relaciones de sucesos en España (1500-1750): 203-216. París / Alcalá de Henares: Publications de la Sorbonne / Servicios de publicaciones de la Universidad de Alcalá.

Ledda, G. 1996. "Contribución para una tipología de las relaciones extensas de fiestas religiosas barrocas», en M.a C. García de Enterría et alii. (eds.), Las relaciones de sucesos en España (1500-1750): 227-238. París / Alcalá de Henares: Publications de la Sorbonne / Servicios de publicaciones de la Universidad de Alcalá

León, M. de 1622. Fiestas de Madrid... en la canonización de San Isidro, San Ignacio, San Francisco Javier, San Felipe Neri, clérigo florentino, y Santa Teresa de Jesús. Madrid.

López Poza, S. 1999. "Peculiaridades de las relaciones festivas en forma de libro», en S. López Poza y N. Pena Sueiro (eds.), La fiesta. Actas del I/ Seminario de Relaciones de Sucesos: 213-222. Ferrol: Sociedad de Cultura Valle Inclán (Colección SIELAE).

Manero, M. a P. 1999. "Las relaciones de las Solemnes fiestas que en toda España se hicieron en la beatificación de la N. B. M. Teresa de Jesús, de Diego de San José», en S. López Poza y N. Pena (eds.), La fiesta: 223-234. Ferrol: Sociedad de Cultura Valle Inclán.
Manrique de Luján, F. 1615. Relación de las fiestas de la ciudad de Salamanca en la beatificación de la santa madre Teresa de Jesús, por Fernando Manrique de Luján. Salamanca: Diego Cusio.

Martín González, J. J. 1991. «Beatificación y canonización de San Ignacio de Loyola. Elementos artísticos de la fiesta», en Ignacio de Loyola, Magister Artium en París 1528-1535: 461-473. San Sebastián: Universidad de Deusto.

Menéndez Peláez, J. 2006. «Propaganda ideológica en el teatro neolatino y romance de los colegios de jesuitas en el Siglo de Oro español», en Teatro neolatino em Portugal no contexto da Europa: 97-126. Coimbra: Universidade de Coimbra.

Monforte y Herrera, F. 1622. Relación de las fiestas que ha hecho el Colegio Imperial de la Compañía de Jesús de Madrid en la canonización de San Ignacio de Loyola y San Francisco Javier. Madrid: Luis Sánchez.

Relación breve de las fiestas que en la ciudad de Córdoba se celebraron a la beatificación de la gloriosa patriarca Santa Teresa de Jesús, fundadora de la reformación de descalzos y descalzas carmelitas. Con la justa literaria que en ella hubo... Por el licenciado Juán Páez de Valenzuela... 1615. Córdoba: Viuda de Andrés Barrera.

Relación de la fiesta que en la beatificación del B. P. Ignacio, fundador de la Compañía de Jesús, hizo su colegio de la ciudad de Granada en catorce de febrero de 1610. 1610. Sevilla: Luis Estupiñán.

Relación de las fiestas que en la ciudad de Tarragona se hicieron en regocijo de la beatificación de la madre santa Teresa de Jesús, incluido en J. Dalmau, Relación de la solemnidad con que se han celebrado en la ciudad de Barcelona las fiestas a la beatificación de la madre s. Teresa de Jesús. 1615. Barcelona: Sebastián Matevad.

Relación de las solemnes fiestas que se hicieron en Salamanca a la canonización de Santa Teresa. 1623. Salamanca: Antonia Ramírez.

Relación sencilla y fiel de las fiestas que el rey don Felipe IV... hizo al patronato de sus reinos... que dio a la gloriosa virgen Santa Teresa de Jesús, 1627. Madrid: Juan González.

Renales, G. A. 1991/1993. "Una aproximació a los libros de fiestas barrocos», en La festa religiosa barroca: 59-73. Studi Ispanici.

Romera Castillo, J. 1998. "Compendio literario en honor de Santa Teresa», en J. Romera Castillo, Calas en la literatura española del Siglo de Oro: 255-325. Madrid: Universidad Nacional de Educación a Distancia.

San José, D. 1615. Compendio de las solenes fiestas que en toda España se hicieron en la beatificación de N. M. S. Teresa de Jesús, fundadora de la reformación de Descalzos y Descalzas de N. S. del Carmen. Madrid: Viuda de Alonso Martín.

Vega, Lope de 1622. Relación de las fiestas que la insigne villa de Madrid hizo en la canonización de su bienaventurado hijo y patrón San Isidro. Madrid: Viuda de Alonso Martín. 